\title{
Summing spectra in gamma spectrometry for improving detection of low-level radionuclides in aerosol samples
}

\author{
E. Barker, X. Cagnat, P. Bouisset, D. Mekhlouche, S. Aubry and R. Gurriaran \\ IRSN/DEI/STEME/Environmental Radioactivity Measurement Laboratory, Bat. 501, \\ Bois des Rames, 91400 Orsay, France, e-mail: evelyne.barker@irsn.fr
}

\begin{abstract}
In the frame of IRSN's French radioactivity observatory, aerosol samples are collected in a ten-days basis in different locations and measured by gamma spectrometry. For some studies, it is necessary to have the average of a radionuclide in aerosol samples, i.e. monthly or annually. Gamma spectrometry measurement of artificial radionuclides such as ${ }^{137} \mathrm{Cs}$ is becoming more difficult due to decreasing radioactivity levels. Individual measurements are sometimes below the minimum detectable activity (MDA) even when low-background measurement procedures are used. In these cases, how can a MDA in an average computation be taken into account? In order to acquire this mean value, the analysis can be performed on the annual spectrum corresponding to a running sum of each individual spectrum. As for the sample, the summing is applied for the background spectrum. In this way, the ${ }^{137}$ Cs concentration in aerosols corresponding to the annual mean value is obtained. For aerosols collected in La Reunion, a mean concentration of $0.029 \pm 0.010 \mu \mathrm{Bq} \cdot \mathrm{m}^{-3}$ for ${ }^{137} \mathrm{Cs}$ is obtained, when 25 measurement results on 26 samples are below the MDA. For radionuclides always detected, a good agreement between summing spectrum results and computed mean value is observed.
\end{abstract}

\section{INTRODUCTION}

Extended time series of radioactivity observation serve to study changes in radionuclide concentrations in the various environmental compartments to assess their stocks and their exchanges. This is so for the ${ }^{137} \mathrm{Cs}$ in the atmosphere, that result principally from military nuclear experiments and the Chernobyl accident (1986).

In 2000, the activity concentration of ${ }^{137} \mathrm{Cs}$ determined by direct Ge gamma spectrometry was in the order of $0.4 \mu \mathrm{Bq} \cdot \mathrm{m}^{-3}$ in Metropolitan France (Northern Hemisphere) and ten times less in La Reunion (Overseas, Southern Hemisphere) for aerosol samples taken over a period of ten days (daily rate of $400 \mathrm{~m}^{3} \cdot \mathrm{h}^{-1}$ ). In many cases, the ${ }^{137} \mathrm{Cs}$ concentration was less than the minimum detectable activity (MDA) for measurements taken with standard GeHP detectors with over $50 \%$ relative efficiency and counting times of 48 hours.

To reduce the detection limit, low background measuring devices have been selected and passive or active protections with respect to ambient radioactivity and cosmic radiation set in place [1]. These improvements are not always sufficient, however, to compensate for the constant reduction in ${ }^{137} \mathrm{Cs}$ concentration in atmospheric aerosols.

Using the results of these measurements, an effective mean annual dose is incorrectly estimated. How can this mean value be determined from the results of measurements below MDA? These MDA could be replaced by (i) a nil value, (ii) half the value of the MDA, (iii) the MDA value [2] or (iv) they could be ignored [3]. None of these four methods are satisfactory, for they underestimate or overestimate the results and the uncertainty surrounding the mean is debatable. 
One solution is to homogenise the samples taken regularly in a year to obtain a unique annual sampling followed by measurement, but this has the disadvantage of loss of sample individualisation, even their destruction. Following our previous work on obtaining specific, long-term background spectrum by summing several spectra channel by channel [4], we decided to extend the method to measuring samples from specific, low-activity aerosols.

\section{EQUIPMENT AND METHODS}

\subsection{Preparation and gamma spectrometry measurement}

The collection filters for $0.016 \mathrm{~g} . \mathrm{cm}^{-2}$ polypropylene aerosols (48 x $27 \mathrm{~cm}$ rectangle) were compacted using a thermopress to produce a $15 \mathrm{~mm}$ thick cylinder, $72 \mathrm{~mm}$ in diameter. A calibration source with the same dimensions was manufactured to cover the energy range of $46 \mathrm{keV}$ to $2.6 \mathrm{MeV}$.

Samples were measured on low-level background detectors with high relative efficiency (over 50\%). The characteristics of the detectors used for this study can be found in Table 1; one is fitted with a cosmic veto (plastic scintillators) and installed under three metres of borated concrete in the second basement of our laboratory at Orsay [1], the other, very low-level background detector is installed in the Modane underground laboratory (LSM) in the Fréjus tunnel in France [5]. The counting times are a minimum of two days.

Table 1. Characteristics of low background detectors.

\begin{tabular}{cccc}
\hline Detector & $\begin{array}{c}\text { Relative efficiency } \\
\text { window }\end{array}$ & $\begin{array}{c}\text { HPGe cristal } \\
\text { Diameter }[\mathrm{mm}]-\text { Thickness }[\mathrm{mm}]\end{array}$ & Specificity \\
\hline 640 & $\begin{array}{c}64 \% \\
\text { Carbon fiber }\end{array}$ & $65.4-76.5$ & $\begin{array}{c}\text { Low-level background equipped with } \\
\text { a veto cosmic device }\end{array}$ \\
$52 \mathrm{E}$ & $\begin{array}{c}50 \% \\
\text { Aluminium }\end{array}$ & $63.6-64.0$ & $\begin{array}{c}\text { Ultra-low-level background located in } \\
\text { an underground laboratory (4800 m w.e) } \\
\text { (Modane, Fr) }\end{array}$ \\
\hline
\end{tabular}

\subsection{Spectrum summing method used}

Despite the stability of the electronics, slight variations are encountered in the energy-channel relationship. To maintain a resolution of the summed spectrum peaks identical to those of individual spectra obtained with the same detector, a multi-channel spectra relocation is performed. The method used is similar to that presented by Loska [6].

\section{RESULTS AND DISCUSSION}

The results from two aerosol collection stations are presented to illustrate the interest of this method. The first example is of three aerosol samples taken during March 2002 at La Seyne s/mer where ${ }^{137} \mathrm{Cs}$ is still quantised. These samples were measured with a low-level background detector fitted with a cosmic veto. The second example relates to 26 aerosol samples taken during the year 2000 in La Reunion, where ${ }^{137} \mathrm{Cs}$ was quantised once, whereas 25 results are below the MDA. 


\subsection{Summing of the La Seyne s/mer aerosol spectra}

Measuring the three aerosol filters taken at La Seyne s/mer (counting time 160,000 s) quantised ${ }^{137} \mathrm{Cs}$, ${ }^{7} \mathrm{Be},{ }^{40} \mathrm{~K}$, ${ }^{22} \mathrm{Na}$ and ${ }^{210} \mathrm{~Pb}$ (Table 2). The three spectra were summed and a specific long-term background spectrum, the sum of six spectra of 240,000 or 320,000 s, was subtracted. For all the radionuclides studied, the mean values (arithmetical average) calculated from the three measurement results are in total agreement with the values produced by the spectra sum (Table 2).

Having summed the spectra, some radionuclides unquantised during standard analyses $\left({ }^{228} \mathrm{Ac}\right.$ in the example treated) are now quantised. Note also the improvement in MDA by a factor of 2 in this example for the other radionuclides.

\subsection{Summing of the La Reunion aerosol spectra}

Aerosol samples from the Southern Hemisphere [7] were measured with a very low-level background detector installed in the Modane underground laboratory (LSM), in other words protected by 4,800 water-equivalent metres (m w.e) against cosmic radiation. ${ }^{137} \mathrm{Cs}$ is, however, very rarely detected in these samples. For La Reunion, 26 aerosol filters were measured between January and October 2000 and ${ }^{137} \mathrm{Cs}$ was quantised once at $0.05 \pm 0.02 \mu \mathrm{Bq} . \mathrm{m}^{-3}$. It is therefore impossible to give a representative mean value for this sampling period. A representative result for the period is obtained by summing the 26 spectra (112 days of accumulated measurements, Figure 1) and using a specific summed background spectrum (111 measurement days) (Table 3).

Table 2. Activity concentrations obtained with the three aerosol filters collected in March 2002 at La Seyne s/mer and mean calculated value (coverage factor: 2 ) compared with the value obtained after summing of the three spectra.

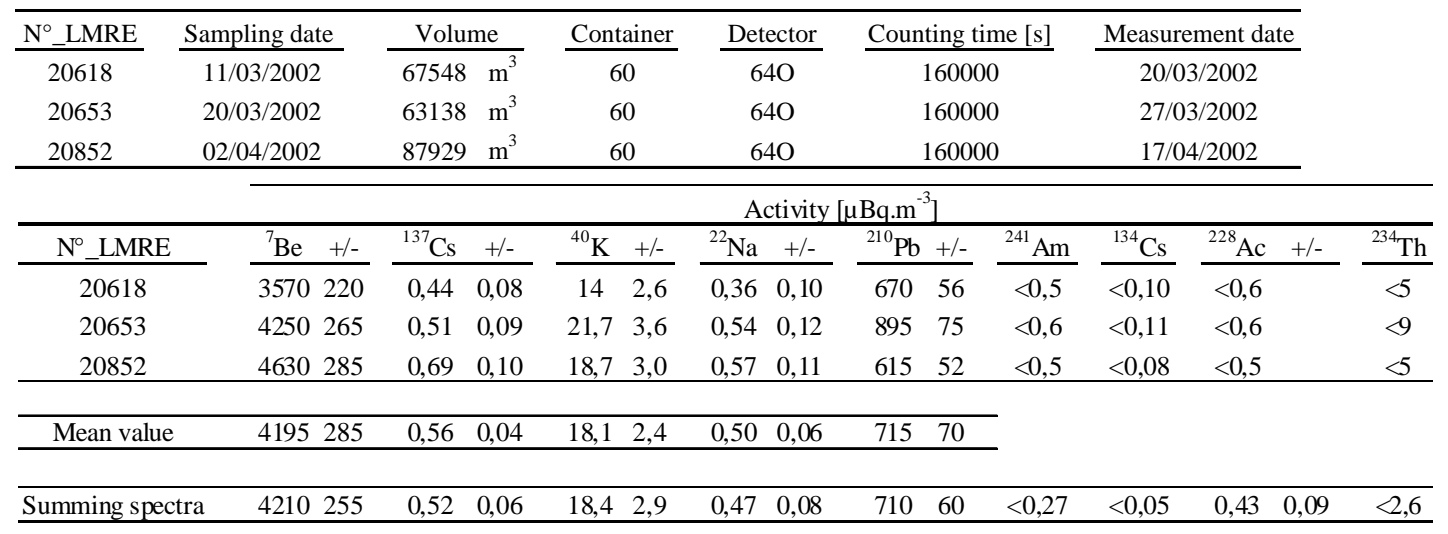

Table 3 shows that the mean value calculated for ${ }^{40} \mathrm{~K},{ }^{22} \mathrm{Na}$ and ${ }^{210} \mathrm{~Pb}$, quantised in the 26 individual spectra, and the value obtained by the spectra sum are in agreement. No comparison can be made for ${ }^{7}$ Be given its short period of radioactive decay $\left(\mathrm{T}_{1 / 2}=53\right.$ days). A value of $0.029 \pm 0.010 \mu \mathrm{Bq} \cdot \mathrm{m}^{-3}$ is obtained for ${ }^{137} \mathrm{Cs}$, the only artificial radionuclide identified in the spectrum sum, whereas ${ }^{137} \mathrm{Cs}$ could only be quantised by a single measurement from the 26 samples analysed. 


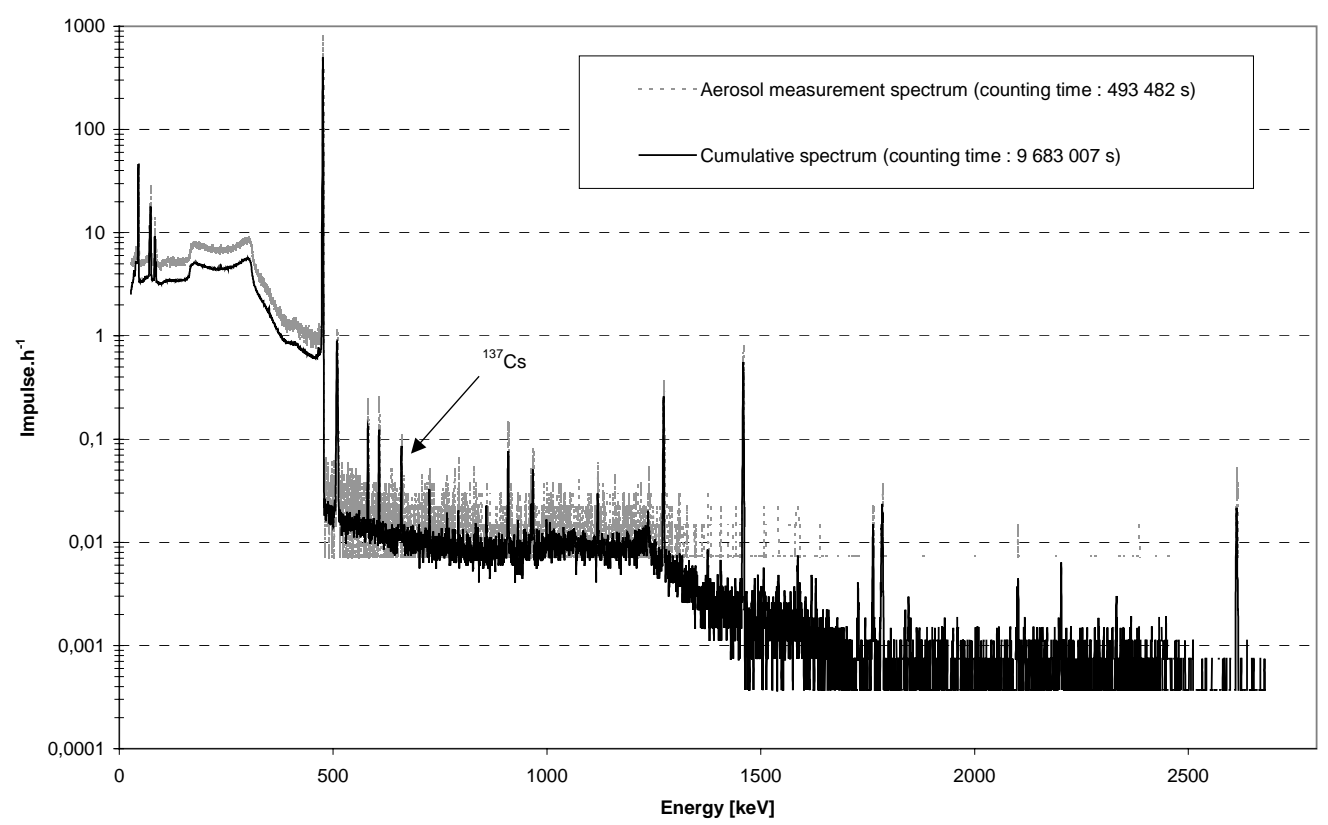

Figure 1. Gross spectrum sum (26 accumulated measurements) for the La Reunion aerosols in 2000 superimposed on the spectrum from the second ten-day period in April 2000.

Table 3. Mean activity concentration calculated from 26 independent aerosol measurements on La Reunion and the one subtracted from the spectrum sum (coverage factor: 2).

\begin{tabular}{ccccc}
\hline & \multicolumn{4}{c}{ Activity $\left[\mu \mathrm{Bq} \cdot \mathrm{m}^{-3}\right]$} \\
\cline { 2 - 5 } & ${ }^{137} \mathrm{Cs}$ & ${ }^{40} \mathrm{~K}$ & ${ }^{22} \mathrm{Na}$ & ${ }^{210} \mathrm{~Pb}$ \\
\cline { 2 - 5 } Value below MDA on 26 measurements & 25 & 0 & 0 & 0 \\
Mean activity concentration & & $7,4 \pm 1,9$ & $0,34 \pm 0,09$ & $132 \pm 31$ \\
Spectrum sum & $\mathbf{0 , 0 2 9} \pm \mathbf{0 , 0 1 0}$ & $7,7 \pm 2,6$ & $0,34 \pm 0,11$ & $130 \pm 40$ \\
\hline
\end{tabular}

\section{CONCLUSION}

The summing of gamma spectra for series of measurements is an ideal way of increasing the counting statistic. This method, originally developed to improve the sensitivity of specific background spectrum measurements [4], has been extended to aerosol sample measurement. The improvement and accuracy of the analysis thus performed have been tested in two particular situations, with three samples collected at La Seyne s/mer and 26 samples collected on the island of La Reunion. In both cases, we have obtained good convergence of results for ${ }^{40} \mathrm{~K},{ }^{22} \mathrm{Na}$ and ${ }^{210} \mathrm{~Pb}$ determined by an arithmetical average of the series of individual results and those obtained by analysis of the spectrum sum. The values of ${ }^{137} \mathrm{Cs}$ also converge well in the first case. In the second case, the ${ }^{137} \mathrm{Cs}$ activity is $0.029 \pm 0.010 \mu \mathrm{Bq} \cdot \mathrm{m}^{-3}$ at the end of the spectrum sum analysis, whereas the radionuclide was only quantised once (25 times in MDA) out of the 26 individual measurements. 


\section{References}

[1] P. Bouisset, D. Calmet, Esarda report EUR 17312, 73-81 (1997).

[2] C.C. Travis, M.L. Land, Environ. Sci. Technol 24 (7), 961-962 (1990).

[3] R.O. Gilbert, R.R. Kinnison, Health Physics 40, 377-390 (1981).

[4] E. Barker, P. Bouisset, X. Cagnat, R. Gurriaran, G. Kerlau, D. Mekhlouche, in Congrès Journées de spectrométrie gamma et X 2002 (oct. 2002), Bulletin du Bureau National de Métrologie 2003-2 n¹23 ISSN 0982-2232, 131-136 (2003).

[5] X. Cagnat, G. Kerlau, E. Barker, P. Bouisset, D. Calmet, in Actes des 'Journées techniques de la CETAMA : Mesures et Analyses dans les matrices environnementales et biologiques’ Cadarache (14-15 sept. 1999), 419-431 (1999).

[6] L. Loska, Appl. Radiat. Isot. 46 (9), 949-953 (1995).

[7] P. Bouisset, E. Barker, O. Masson, R. Gurriaran, X. Cagnat, D. Mekhlouche, S. Aubry, M. Hadjaj, L. Saey, Radioprotection 39 n³ (2004). 